\title{
A expansão islamista na Europa: a transnacionalização de movimentos fundamentalistas muçulmanos e razões para a radicalização da diáspora islâmica na Europa
}

The Islamic expansion in Europe: the transnationalization of muslim fundamentalist movements and reasons for the radicalization of the Islamic diaspora in Europe

\section{Leandro Loureiro Costa ${ }^{1}$}

\section{Resumo}

A presente pesquisa buscou apresentar possíveis motivações para o crescimento da radicalização das comunidades islâmicas na Europa, através de uma visão cultural. Dentre as principais razões para a reislamização de imigrantes muçulmanos, foram expostos a globalização, que possibilita o estabelecimento de redes transnacionais, o esforço de países islâmicos na promoção cultural e a tendência natural de migrantes manterem seus costumes de origem.

Palavras-chave: islamismo; diáspora; Europa.

\section{Abstract}

This research aimed to present possible motivations for the growing radicalization of Islamic communities in Europe, through a cultural vision. Among the main reasons for the re-islamization of muslim immigrants, the globalization, which allows for the establishment of transnational networks, the efforts of Islamic countries in promoting culture, and the natural tendency of migrants keep their home customs were exposed.

Key-words: Islamism; Diaspora; Europe.

\section{Considerações iniciais e definições sobre o islã e o islamismo}

Desde os anos 2000, a Europa tem sido acometida por uma série de atentados terroristas perpetrados por grupos extremistas islâmicos. Os acontecimentos perpassam por uma série de grandes ataques e também pequenos assassinatos e casos de vandalismo ligados a indivíduos que diziam agir em nome da religião muçulmana. Paris, Bruxelas,

\footnotetext{
1 Mestre em Relações Internacionais pelo Programa de Pós-Graduação em Relações Internacionais na Universidade do Estado do Rio de Janeiro.
} 
Londres e Madri já foram vítimas desses grandes atentados empreendidos por organizações terroristas como a Al-Qaeda e o Estado Islâmico (Isis). Muitos dos responsáveis nasceram e cresceram na Europa, receberam educação ocidental e, mesmo assim, acabaram se envolvendo com grupos fundamentalistas, tendo sido recrutados para a realização desses ataques. Esses diversos eventos violentos, conectados ao extremismo islâmico, retiraram o véu que cobria um velho/novo problema na Europa: o aumento da radicalização da sociedade islâmica graças à presença de redes fundamentalistas muçulmanas na região.

A palavra muçulmano designa o seguidor da religião islâmica. É derivada da palavra árabe transliterada muslim, que significa "aquele que se submete". Pete Mandaville (2001, p. 54) afirma que o termo muçulmano representa uma autoconsciência que possui uma qualidade identitária relativa ao islã, crença monoteísta definida pelo Alcorão e pelos ensinamentos morais do profeta Maomé. Já o islã, segundo o autor, pode ser analisado como uma manifestação universal que desempenha uma função constitutiva nas comunidades políticas muçulmanas. Para Pete Mandaville, o islã é fluido e suas fronteiras estão em processo constante de mudança.

Peter Demant (2011, p. 14) também procura diferenciar a palavra muçulmano do termo islã. 0 autor conclui que a primeira representa um fenômeno sociológico, enquanto a segunda refere-se estritamente à religião. A partir disso, Demant afirma que países como o Paquistão e a Turquia, por exemplo, não podem ser considerados Estados islâmicos, mas, sim, Estados de maioria muçulmana.

O islã não é uma religião homogênea. Após a morte de Maomé, a comunidade islâmica fragmentou-se em duas grandes subdivisões: os xiitas e os sunitas. 0 primeiro grupo considera que Ali, genro do profeta, é o líder da religião pós-Maomé. Vê como ilegítimos os califados sunitas que assumiram a condução do islamismo após a morte do profeta. Por sua vez, os sunitas seguem a sunna, texto sagrado que acreditam ser baseado nos ensinamentos do profeta (GUELLOUZ, 1997). Ambas as partes se colocaram diversas vezes em lados antagônicos em conflitos, como, por exemplo, na Guerra do Líbano e no conflito entre o Irã e o Iraque na década de 1980.

Embora existam essas divisões dentro do islã, todas as vertentes da religião compartilham uma identidade comum, a muçulmana. Mandeville acredita que perceber o 
islã como uma identificação representativa de um sistema universal que compreende todos os muçulmanos não caracteriza um caso de essencialização.

Essa ideia sobre a questão da umma acaba dialogando com a perspectiva de Benedict Anderson (1993) a respeito da ideia de nação. Para Anderson, a nação é uma "comunidade imaginada", porque até mesmo os indivíduos de uma nação que nunca se conheceram compartilham a percepção de uma solidariedade entre eles. 0 islã não é uma nação, mas, sim, uma religião. Entretanto, a umma é um conceito que representa uma identidade imaginada. Os muçulmanos do mundo inteiro compartilham o islã. 0 turco muçulmano, assim como o árabe muçulmano, deve seguir os dogmas centrais da religião, mostrados no início deste capítulo. Os laços religiosos não impedem a existência de laços tribais ou nacionais.

Além das divisões e da noção de umma, o islã possui inúmeras correntes políticas que formulam a sua agenda através da doutrina islâmica. Essa situação é o que muitos autores classificam como "islamismo". Esse termo é constantemente utilizado como sinônimo de islã. Entretanto, o primeiro é diferente do segundo, pois abrange outros elementos além da religião e da identidade cultural. Pete Mandaville avalia que o islamismo é um sistema no qual o islã serve como fundamento político. Já Peter Demant (2011) amplia essa visão ao afirmar que o vocábulo islamismo ${ }^{2}$ refere-se a movimentos religiosos radicais em um contexto político, sendo um sinônimo de fundamentalismo islâmico. 0 islamismo utiliza a religião como uma ideologia política. Enquanto isso, o islã é o uso da religião como símbolo de uma identidade

Além de ser analisado dessa maneira, o islamismo deve ser visto como um movimento político. Está estruturado na proposta de um modelo teocrático de Estado e de sociedade como alternativa a valores considerados ocidentais, como o Estado secular e a laicidade. Para os islamistas, a cultura ocidental é fonte de permissividade e consumismo exacerbado, que distorcem a consciência moral do indivíduo.

Castells (1999, p. 29) concebe o fundamentalismo como

[...] a construção da identidade coletiva segundo a identificação do comportamento individual e das instituições da sociedade com as normas oriundas da lei de Deus, interpretadas por uma autoridade definida que atua como intermediária entre Deus e a humanidade.

${ }^{2} \mathrm{O}$ autor também utiliza a palavra islamista para representar os que praticam o islamismo. 
O fundamentalismo religioso é uma das mais importantes fontes de construção identitária, sendo um fenômeno sempre presente nas relações humanas. 0 conceito teve a sua origem nos Estados Unidos, no início do século XX, com a publicação de uma coletânea de livros editada por teólogos evangélicos conservadores e intitulada The fundamentals. Devido à variedade de classificações dentro do cristianismo, como os pentecostais, pietistas e carismáticos, Castells busca em Michael Lienesch uma abordagem sintética sobre o sentido do fundamentalismo cristão. Através dessa concepção, o fundamentalismo parte da ideia de renascimento pessoal por meio da conversão, do arrependimento e da fé. Esse revival individual não apenas forma uma construção de identidade social como também é capaz de edificar objetivos políticos e ordenações sociais.

Dessa forma, os muçulmanos não fundamentalistas interpretam a sharia apenas como um referencial para chegar a Deus, enquanto os fundamentalistas unem a jurisprudência (fiqh) com a sharia. Castells (1999, p. 31) prossegue o seu raciocínio afirmando que existe uma diversidade de fundamentalismos dentro do islã, que são classificados através da forma como essas divisões islamistas interpretam a religião.

No livro Fascism: past, present, future (1996), Walter Laqueur dá ao islamismo um tom de ideologia ao compará-lo ao fascismo, classificando o primeiro termo como "fascismo clerical". Para o autor, o islamismo possui semelhança com os fascistas da Europa no século XX, que defendiam suas ações com base na militância nas ruas e na utilização das massas como ferramenta (2007, p. 93). 0 autor defende que o fundamentalismo não é um problema exclusivamente islâmico, entretanto, pondera que o islã tem sido a religião em que os grupos fundamentalistas vêm obtendo mais sucesso. O fundamentalismo religioso islâmico, na grande maioria dos casos, expõe a necessidade inquebrantável da construção de uma estrutura política baseada nas leis das escrituras do islã. Dessa forma, pode ser avaliado como um sinônimo de islamismo.

Sobre as origens do fundamentalismo, Demant considera que este surge a partir de uma reação à globalização e à "opção ocidentalizante" e ocorre concomitantemente à expansão da religião islâmica. A ocidentalização ocorreu no Oriente Médio como um nacionalismo secular. No chamado mundo muçulmano, apenas na Turquia o movimento nacionalista laico perdura até os tempos hodiernos. Os iranianos e os árabes se empenharam nas tentativas de movimentos políticos patrióticos e nacionalistas baseados 
na concepção de Estado-nação moderno, entretanto acabaram produzindo governos ditatoriais. A incapacidade dos regimes árabes em lidar com Israel na Guerra dos Seis Dias, em 1967, a falência da cooperação interárabe para controlar a crise no Líbano, as crises do petróleo e o conflito entre Irã e Iraque foram as causas para a derrota da legitimidade do nacional-desenvolvimentismo-estadista.

Foi a partir do colapso desse modelo e do esgotamento dos Estados de maioria muçulmana no Oriente Médio em seguir políticas consideradas ocidentais que o islamismo/fundamentalismo islâmico emergiu. 0 autor considera que o período de colonização empreendido pelas potências europeias sobre os Estados muçulmanos, através da implementação de um controle político e militar, resultou em um processo de humilhação do islã, criando, dessa forma, um ambiente propício para a emergência do islamismo (DEMANT, 2011, p. 200-201).

Outro autor que possui essa mesma inclinação a respeito do papel da humilhação na emergência do fundamentalismo é Dominique Moïsi (2009). Em sua obra A geopolítica das emoções, ele caracteriza o sentimento de humilhação presente no mundo muçulmano como uma das causas para o fortalecimento do fundamentalismo religioso. A humilhação reflete o sentimento de impotência que tem sua origem na falta de controle sobre a vida do ponto de vista individual e até do ponto de vista coletivo. Nesse último caso, a humilhação afeta a nação, a comunidade religiosa, ou o povo. 0 autor afirma que a humilhação ocorre quando existe a percepção de que o Outro invadiu e tornou totalmente dependente o domínio privado do Eu.

O autor acredita que, no mundo muçulmano, com algumas exceções (Emirados Árabes Unidos, que soube aliar a cultura de consumo ocidental com as tradições religiosas), o sentimento de humilhação produziu um panorama de desesperança e revanchismo. A causa principal para isso é o sentimento de declínio histórico ou o medo da decadência. São emoções que permeiam e permearam todas as nações, culturas e civilizações (MOÏSI, 2009, p. 60).

Entretanto, o sentimento de humilhação apregoado por Moïsi, por si só, não é capaz de explicar o crescimento da radicalização nas comunidades muçulmanas na Europa. Na realidade, deve-se buscar uma maior elucidação a partir da diáspora muçulmana europeia em um contexto de globalização. Portanto, na próxima etapa da 
pesquisa, serão esmiuçados o caráter transnacional da identidade islâmica e suas implicações para o processo de radicalização.

\section{A diáspora muçulmana na Europa}

É na Europa onde se localiza a maior diáspora muçulmana e onde há a maior evidência de transnacionalização dos valores islamistas para as comunidades de imigrantes seguidores da religião. Os muçulmanos são parte significativa da população do continente. Segundo o Pew Research, nos países da União Europeia (UE), a parcela de muçulmanos é de cerca de 13 milhões de indivíduos, aproximadamente 6\% dos habitantes da UE em 2010, tendo avançado 2\% em comparação à quantidade de muçulmanos, imigrantes e "nativos" convertidos, em 1990 (HACKETT, 2015).

Após a efetivação das comunidades de imigrantes muçulmanos na Europa, estes tiveram que lidar com a sua identidade coletiva em um ambiente onde a identidade dominante não era a muçulmana. Os islamistas no continente europeu convivem com duas opções antagônicas em relação à identidade autóctone: a assimilação ou a reafirmação identitária.

De acordo com Djelloul e Maréchal (2015, p. 90), a construção social da identidade da diáspora muçulmana é resultado de uma relação dialética entre a comunidade islâmica e o ambiente social. Segundo as autoras, a mobilização dos muçulmanos está ligada à interação deles com a sociedade ocidental europeia, o que estabelece alterações nas dinâmicas de relacionamento entre religiões e culturas diferentes, sendo, assim, capaz de mobilizar temas como a globalização, o nacionalismo, o multiculturalismo, etc. Essa dinâmica é favorecida pela globalização.

Dessa maneira, o processo de mundialização, que se refere à modernização de processos tecnológicos que impactam a economia mundial na velocidade da informação, da comunicação e do transporte, tem possibilitado o aumento da interdependência econômica entre Estados e indivíduos, o que acaba reduzindo o entendimento em relação ao tempo e ao espaço, produzindo conexões transnacionais. Sobre as relações transnacionais, Kennedy e Roudometof (2002, p. 2) propõem que estas devem ser entendidas como fenômenos sociais que não estão restritos aos fluxos migratórios. Na realidade, as interações transnacionais acabam por influenciar a identidade de indivíduos que estão presentes em diversos tipos de associações e redes coletivas. 
Todas essas formas de associação humana que possuem valores e sentidos cognitivos compartilhados a partir de um senso comum em torno de um grupo identitário são chamadas de comunidades por Kennedy e Roudometof (2002, p. 6). Essas comunidades são delimitadas por sua identidade coletiva e, na era da globalização, tornam-se independentes das relações interpessoais e da questão da localidade. A imigração, então, foi capaz de possibilitar esse panorama através do fluxo transnacional de culturas.

Estes "transmigrantes", como são chamados pelos autores, incentivados pelo recrudescimento da globalização, têm a oportunidade de escolher entre manter suas conexões com seu local de origem ou preferir o caminho da assimilação. Em relação ao contato dos "transmigrantes" com um novo ambiente cultural, repleto de diferenças, Kennedy e Roudometof seguem uma abordagem semelhante à proposta por Manuel Castells (1999, p. 25). De acordo com o último autor, essa relação acaba criando um tipo de identidade que produz bolsões de resistência coletiva diante de uma opressão. Nesse caso, a opressão pode ser entendida como um sentimento de exclusão ocasionado pela sensação de não pertencimento a uma comunidade diferente.

Já Demant (2011, p. 174) encara o dilema de isolamento/assimilação muçulmana na Europa como uma dubiedade ocasionada devido ao fim da imigração trabalhista com a crise do petróleo de 1974. Os muçulmanos que não voltaram para seus Estados de origem tiveram que lidar com essa questão sendo "transeuntes em diásporas mais ou menos permanentes". Para analisar o problema de isolamento/assimilação, Demant afirma que três fatos fazem parte dessa relação. 0 primeiro é que a grande maioria desses imigrantes vivia em Estados majoritariamente muçulmanos. Dessa forma, não tinha vivenciado a sensação de ser minoria. Às vezes, essa minoria era até mesmo ilegítima devido à restrição de seguir outra religião em alguns Estados islâmicos.

0 segundo fato apontado pelo autor que impacta a relação de isolamento/assimilação é que as comunidades muçulmanas são fragmentadas em diversas etnias, como turcos, marroquinos, somalianos, curdos e árabes. Fora do islã, essas comunidades são muito diferentes entre si. Entretanto, nas gerações posteriores, as dessemelhanças entre os grupos diminuíram com o maior contato entre as comunidades muçulmanas. 0 terceiro fato é a pobreza. A maioria dos islamistas europeus é marginalizada e se encontra em condições de desfavorecimento. 
Em seu livro The global resurgence of religion and the transformation of international relations, Scott M. Thomas (2005) avalia que as diásporas são exemplos de consequências da globalização. Além disso, aliada a esse fenômeno, a globalização, segundo o autor, está alterando o panorama da religião no mundo. Primeiramente, a globalização está transformando o sentido da religião e o que se constitui como atores internacionais religiosos. Nesse ponto, Thomas contesta a tese do "choque de civilizações", de Samuel Huntington, a qual pretendeu dividir a religião, nas relações internacionais, em blocos estáticos. Para Thomas (2005, p. 98), a realidade da religião no século XXI está longe de ser fixa como apontou Huntington.

Além de por meio da diáspora muçulmana, o islã se faz presente na Europa através de instituições domésticas e transnacionais, sendo a região uma importante fonte de pensamento político islamista. Alguns dos grandes movimentos políticos islâmicos estão localizados na Europa desde a década de 1960. Nessa época, membros e adeptos desse grupo migraram para o continente europeu. Com o tempo, foram capazes de construir uma rede de mesquitas, de organizações islâmicas e de instituições de caridade (VIDINO, 2005).

Os islamistas formaram networks sociais que atuam diretamente nos indivíduos. Adquiriram, com o tempo, a capacidade de adaptação às novas tecnologias, desenvolvendo os meios de comunicação das redes com o seu público-alvo, as gerações mais jovens de muçulmanos. Entretanto, mesmo utilizando os avanços tecnológicos como ferramenta, as networks islamistas defendem a tradição cultural como princípio norteador de suas demandas.

Quanto à atividade dos grupos islamistas na Europa, Frank Peter afirma que estes estão preocupados com demandas básicas da população de imigrantes muçulmanos, como a construção de mesquitas com minaretes, instrução religiosa básica e a mobilização de jovens muçulmanos. Nesse contexto, os imãs e outros atores educacionais desenvolvem um papel importante na criação de conexões entre as instituições muçulmanas e as estruturas políticas e legais do Estado.

Os primeiros grupos islamistas se formaram na Europa a partir da década de 1970. A maioria inspirava-se na Irmandade Muçulmana (IM), seguindo seus padrões e ensinamentos. Instalaram-se através da criação de grupos para a juventude e para o 
público feminino, a partir de publicações de revistas, centros de propaganda, centros educacionais e think tanks (VIDINO, 2010).

Após 40 anos de atuação na Europa, sobretudo na parte ocidental, as organizações inspiradas na IM se multiplicaram em grandes ramificações que se localizam em quase todos os países da região. Os agrupamentos inspirados na IM tornaram-se a principal organização islamista em praticamente todos eles, superando as outras ramificações que não seguem o viés da IM. Dessa forma, como afirma Vidino (2010, p. 107), tornaram-se o único movimento competente para estabelecer organizações bem estruturadas em praticamente todos os Estados europeus. $\mathrm{O}$ autor acredita que somente essas ramificações da IM foram capazes de criar uma liga islamista pan-europeia.

Lorenzo Vidino acredita que o sucesso da IM se deve principalmente à capacidade da organização em captar recursos. No processo inicial de estabelecimento das ramificações da IM, o financiamento de países do golfo Árabe, sobretudo da Arábia Saudita, possibilitou a formação de uma rede financeira estruturada, que pôde auxiliar e patrocinar as atividades das organizações guarda-chuva.

Estes financiamentos iniciais deram-se graças aos empenhos da família real saudita na divulgação da ideologia do uaabismo, através da criação da Liga Mundial Muçulmana em 1962. A liga tinha o intuito de propagar o islã pelo mundo e promover os ensinamentos da sharia, a lei islâmica. Na década de 1970, a atuação na construção de mesquitas e no financiamento de instituições muçulmanas cresceu muito devido ao aumento do preço do petróleo e ao consequente crescimento de recursos financeiros disponíveis.

O comportamento da Arábia Saudita ao financiar organizações islamistas missionárias pelo planeta, sobretudo a IM, é explicado pela teoria da interdependência complexa (KEOHANE; NYE, 1977) e do soft power (NYE, 2004). Na primeira, a "interdependência complexa”, as relações internacionais são permeadas de várias redes de interação, em que não há diferença hierárquica entre os chamados high politics (assuntos militares) e os low politics (assuntos culturais e econômicos). Na teoria da interdependência complexa, os atores protagonistas nas relações internacionais continuam sendo os Estados e os governos. Porém, estes devem conviver agora com instituições não governamentais e atores subestatais, formando uma relação assimétrica. Já o conceito de soft power é "a habilidade de alcançar um determinado objetivo através 
da atração ao invés da coerção. 0 soft power se manifesta através da capacidade de atração da cultura de um país, das suas ideias e ações políticas" (NYE, 2004, p. 10).

Nesse caso, tanto a Arábia Saudita quanto o Qatar promovem organizações não governamentais e instituições em outros países com o intuito de divulgar as doutrinas islamistas ultraconservadoras que guiam os governos desses países, o uaabismo. Além de impulsionar a religião islâmica sob a maior parte do patrocínio de mesquitas na Europa, a doutrina também incentiva os muçulmanos das diásporas a não se integrarem às comunidades majoritárias que os abrigam. A integração representa uma ameaça à crença em Alá e nos princípios da fé islâmica (BERGMAN, 2016).

Gallarotti e Al Filali (2014, p. 11) afirmam que a promoção do pan-islamismo é a agenda central de política externa da Arábia Saudita. O pan-islamismo é uma ideia estruturada na ideia de umma e na solidariedade em relação à comunidade muçulmana espalhada pelo mundo. A Arábia Saudita, além de ser o centro da cultura árabe, é o núcleo da religião islâmica. A Caaba, o primeiro lugar de adoração a ser construído no mundo de acordo com o islã, se localiza nesse país, sendo um centro de peregrinação. ${ }^{3}$ Além disso, Medina, outra cidade sagrada para os muçulmanos, fica em território saudita. Todo ano ela recebe cerca de 2 milhões de peregrinos durante a alta temporada e muitos outros no resto do ano.

0 autor ainda destaca que o soft power saudita se manifesta em duas formas organizacionais, a Organização para a Cooperação Islâmica e a já mencionada Liga Mundial Muçulmana. Essas duas organizações formam um "caminho coletivo" pelo qual as diásporas muçulmanas podem ser influenciadas pela Arábia Saudita. Dessa forma, conclui-se que a principal motivação dos sauditas ao financiarem diversas instituições islâmicas pelo mundo, sobretudo na Europa, é manter o seu status como capital do mundo muçulmano.

\section{A reislamização}

Como foi afirmado anteriormente, os imigrantes muçulmanos enfrentam dilemas particulares na relação com as sociedades dos Estados que os hospedam. Os obstáculos são resumidos na dificuldade dessas sociedades em integrar as comunidades de

\footnotetext{
${ }^{3}$ Os ensinamentos do islã recomendam que o muçulmano vá até a Caaba pelo menos uma vez na vida.
} 
migrantes. 0 preconceito e a condição social da diáspora muçulmana também são fatores que dificultam a integração plena dos imigrantes na sociedade europeia.

Esse atributo da diáspora muçulmana na Europa facilita o recrutamento de imigrantes para grupos islamistas que, por sua vez, desenvolveram-se a ponto de poder atuar na Europa Ocidental. Esses movimentos são vistos como um refúgio social e como a possibilidade de voltar às origens, como uma rememoração da terra natal e em resposta à constante marginalização das comunidades de imigrantes na UE.

0 processo de globalização, através da evolução tecnológica dos meios de transporte e de comunicação, possibilitou que os movimentos islamistas pudessem dividir suas atenções, focando ao mesmo tempo a militância em seus países de origem e esforços nos regimes seculares pelo mundo, sobretudo ocidentais. A partir dessa condição, a Europa apresenta um ambiente propício para a reprodução de agrupamentos fundamentalistas. A liberdade de movimento de pessoas entre os países é outro fato que facilita a efervescência desses grupos antiocidentais quanto à incapacidade dos governos de monitorar esses movimentos.

Sobre a radicalização e o recrutamento de muçulmanos imigrantes por grupos jihadistas, Magnus Ranstorp (2010, p. 2-3) divide as contribuições da academia em três direções: a primeira, de acadêmicos que priorizam o papel da dinâmica da religião; a segunda, dos que preferem analisar o fenômeno da radicalização através da teoria de movimentos sociais e que buscam compreender o papel dessas organizações como uma estrutura capaz de atrair seguidores para esses tipos de grupo; já a terceira e última direção busca analisar o processo de radicalização a partir das relações internacionais e da política externa.

Entretanto, o autor propõe que a radicalização e a reislamização devem ser vistas como uma situação multicausal, não havendo um único fator decisivo para a ocorrência desse panorama; é um "caleidoscópio de fatores". Por esse motivo, o autor conclui que existem causas internas e externas para o arrefecimento da reislamização. Alguns dos fatores internos são a estigmatização pública, a polarização política, a alienação social, a presença de imãs radicais que glorificam a jihad e a discriminação (RANSTORP, 2010, p. 4). 
Já os motivos externos para a islamização da diáspora muçulmana, segundo Ranstorp, consideram a política externa ocidental como uma causa da radicalização de indivíduos muçulmanos. As ações ocidentais no mundo muçulmano produzem, ativa e passivamente, um sentimento de injustiça através das intervenções nessas regiões, configurando, dessa forma, outra contribuição para a radicalização da diáspora islâmica na Europa e para o envolvimento de indivíduos em grupos terroristas. Ranstorp acredita que tanto os motivos internos quanto os externos acabam sendo interdependentes, impossibilitando uma relação causal entre eles.

Entretanto, existe uma perspectiva de que há, por parte da diáspora muçulmana na Europa, uma tendência natural de manutenção de lealdade às suas comunidades de origem, algo comum em todos os grupos de migrantes. A lealdade é acrescida da influência da globalização através da modernização dos meios de comunicação e de transporte, o que permite que o imigrante mantenha contato com símbolos que remetem à sua ascendência identitária. Esse fator, aliado ao multiculturalismo, que favorece a penetração de grupos islamistas, tem função importante na expansão do fundamentalismo muçulmano na Europa.

Essa conjunção é explicada por Stuart Hall (2006) ao afirmar que a diáspora, em um background de globalização, está exposta a contradições em relação à identidade. Ao mesmo tempo em que os fluxos migratórios demandam uma dinâmica cultural nova baseada no hibridismo (tradução cultural), também abrem caminho para tentativas de restauração de identidades puras (tradição cultural), com o objetivo de reafirmar "a coesão, o fechamento e a Tradição, frente ao hibridismo e à diversidade" (2006, p. 92). A partir dessa dialética da questão identitária na pós-modernidade, percebe-se que, ao mesmo tempo em que há um rápido processo de integração regional em algumas partes do mundo, também existe um revival etnonacionalista e religioso.

Esse renascimento também é analisado por Benedict Anderson (1992), que o chama de "nacionalismo a distância" ou "etnonacionalismo de diáspora". Mesmo vivendo em outro lugar, o imigrante mantém sua lealdade a sua comunidade imaginada. Nesse caso, o conceito de umma entra novamente na discussão. Isso ocorre porque o fundamentalismo islâmico reforça a existência de uma ligação social entre todos os imigrantes que compartilham a identidade muçulmana, não importando suas origens culturais.

\section{Conclusão}


Conclui-se então que, através de uma visão cultural, a concepção de umma entre os imigrantes muçulmanos europeus acaba fazendo mais sentido do que a mesma ideia para muçulmanos em países majoritariamente islâmicos. Nesse último caso, os indivíduos costumam manter suas rivalidades e suas ligações tribais e nacionais, ou com o sunismo ou com o xiismo, sendo a umma colocada em segundo plano. Isso ocorre devido ao processo de alteridade em que o sunita se torna o Outro do Eu xiita. Essa alteridade é manifestada até mesmo entre etnias majoritariamente sunitas. Por exemplo, entre turcos e curdos. Nessa relação, a rivalidade étnica fala mais alto que a identidade sunita compartilhada entre ambos.

Na Europa, a sensação de não pertencimento sentida pela diáspora muçulmana acaba reverberando na identidade religiosa. Dessa forma, os imigrantes terminam buscando um princípio de solidariedade na sua característica identitária mais geral, o islã. Essa "imagem inventada" pelos imigrantes produz uma abertura para a influência de grupos islamistas capazes de criar uma espécie de "network de lembranças" com a terra natal dos membros da diáspora, que veem nessas organizações uma forma de refúgio.

Essa questão também é estimulada por Estados patrocinadores de organizações islamistas, como a Arábia Saudita. A radicalização das comunidades muçulmanas na Europa igualmente ganha impulso graças à globalização, que enfraquece a soberania estatal, permitindo que grupos fundamentalistas islâmicos possam penetrar na região através do estabelecimento de redes transnacionais.

\section{Referências bibliográficas:}

ANDERSON, Benedict. Comunidades Imaginadas: Reflexiones sobre el origen y la difusión del nacionalismo. México: Fondo de Cultura Económica, 1993.

ANDERSON, Benedict. Long-distance Nationalism: World Capitalism and the Rise of Identity Politics. Working paper. Centre for Asian Studies Amsterdam, 1992.

BERGMAN, Judith. Moderate "European" Islam: Stemming Terror with Band Aids. Gatestone Institute, 1 mar. 2016. Disponível em: <http://www.gatestoneinstitute.org/7520/moderate-european-islam>. Acesso em: 10 mar. 2016.

CASTELLS, Manuel. A sociedade em rede. São Paulo: Paz e Terra, 1999.

DEMANT, Peter. 0 mundo muçulmano. 3. Ed. São Paulo: Editora Contexto, 2011.

DJELLOUL, Ghaliya; MARÉCHAL, Brigitte. Muslims in Western Europe in the late twentieth century Emergence and transformations in "Muslim" revindications and collective 
mobilization efforts. In: TOTTOLI, Roberto. Routledge Handbook of Islam in the West. Oxford: Routledge, 2015.

GALLAROTI, Giulio; AL FILALI, Isam Yahia. International Studies. The Soft Power of Saudi Arabia. 49, 2014.

GUELlOUZ, Azzedine. 0 Islão. In: DELUMEAU, Jean. As Grandes Religiões do Mundo. Lisboa: Editorial Presença, 1997.

HACKETT, Conrad. Pew Research. 5 facts about the muslim population in Europe.15/01/2015. <http://www.pewresearch.org/fact-tank/2015/01/15/5-factsabout-the-muslim-population-in-europe/> Acesso em: 18 de agosto de 2015.

HALL, Stuart. A identidade cultural na pós-modernidade. Rio de Janeiro: DP\&A, 2006.

HUNTINGTON, Samuel. The Clash of Civilizations? Foreign Affairs, vol. 72, No. 3. 1993.

KENNEDY, Paul; ROUDOMETOF, Victor. Communities Across Borders: New Immigrants and transnational cultures. London: Routledge, 2002.

KEOHANE, Robert; NYE, Joseph. Power and Interdependence: World Politics in Transition. Boston: Little-Brown, 1977.

LAQUEUR, WALTER. Facism: Past, Present, Future. New York: Oxford University, 1996.

MANDAVILLE, Pete. Transnational Muslim Politics: Reimagining the umma. London: Routledge, 2001.

MOÏSI, Dominique. A Geopolítica das Emoções: Como as culturas do Ocidente, do Oriente e da Ásia estão remodelando o mundo. Rio de Janeiro: Elsevier, 2009.

NYE, Joseph. Soft power: the means to success in world politics. Cambridge: Public Affairs, 2004.

RANSTORP, Magnus. Understanding Violent Radicalisation: Terrorist and Jihadist Movements in Europe. London: Routledge, 2010.

THOMAS, Scott M.. The Global Resurgence of Religion and The Transformation of International Relation: The Struggle for the Soul of the Twenty-First Century. New York: Palgrave McMillan, 2005.

VIDINO, Lorenzo. The Muslim Brotherhood's Conquest of Europe. Middle East Quarterly, p. 25-34, 2005.

VIDINO, Lorenzo. The New Muslim Brotherhood in the West. New York: Columbia University Press, 2010.

VLAHOS, Michael. Terror's Mask: Insurgency Within Islam. Joint Warfare Analysis Department, Applied Physics Laboratory, John Hopkins University, maio de 2002. Apud: RANSTORP, Magnus. Understanding Violent Radicalisation: Terrorist and Jihadist Movements in Europe. London: Routledge, 2010. 